
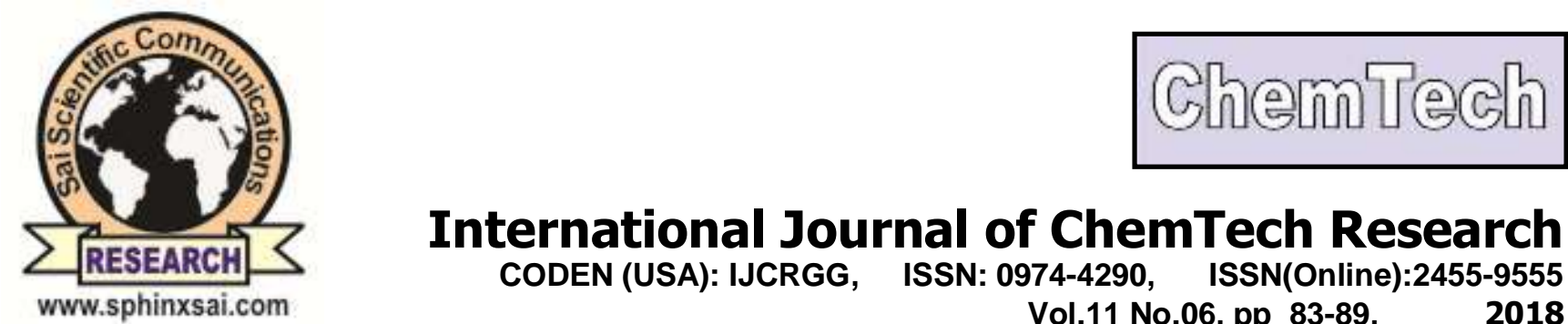

International Journal of ChemTech Research CODEN (USA): IJCRGG, ISSN: 0974-4290, ISSN(Online):2455-9555

Vol.11 No.06, pp 83-89,

2018

\title{
Emerging Technique for Recent Construction of Road Pavements by Pervious Concrete
}

\author{
Arivalagan.S \\ Department of Civil Engineering, Dr.M.G.R.Educational and Research Institute \\ Chennai,TN,India.
}

\begin{abstract}
The importance of this research article is to summarize literature on permeable pavements, and highlight current trends in research and industry to recommend future areas of research and development. Permeable paving is a range of sustainable materials and techniques for permeable pavements with a base and sub base that allow the movement of storm water through the surface.Permeable Pavements is a comprehensive resource for the proper design, construction, and maintenance of permeable pavement systems that provide a transportation surface and a best management practice for stormwater and urban runoff. A cornerstone for low impact development and sustainable site design, permeable pavements are considered a green infrastructure practice. They offer many environmental benefits, from reduced stormwater runoff and improved water quality to better site design and enhanced safety of paved surfaces. Commonly used for walkways, driveways, patios, and low-volume roadways as well as recreational areas, parking lots, and plazas, permeable pavements are appropriate for many different land uses, particularly in highly urbanized locations.This volume synthesizes today's knowledge of the technology, drawing from academia, industry, and the engineering and science communities. It presents an overview of typical permeable pavement systems and reviews the design considerations. Detailed design, construction, use, and performance information is provided for porous asphalt, pervious concrete, permeable interlocking concrete pavement, and grid pavements. Fact sheets and checklists help to successfully incorporate permeable pavement systems into design projects. At present this an emerging technologies for green technology in the construction field.Permeable Pavements is an essential reference for engineers, planners, landscape architects, municipalities, transportation agencies, regulatory agencies, and property owners planning to implement this best management practice for stormwater and urban runoff. Increase subsurface water level, thus one way to harvest storm water. Fly ash is generated in huge quantity in thermal power stations. The disposal of fly ash is also a major socio-economic problem. So the use of fly ash up to $10-30 \%$ as a replacement to a cement can overcome this problem. The use of fly ash will reduces the construction cost and also solve disposal problem. Porous pavement is unique and effective means to meet growing environmental demands.
\end{abstract}

Key Words : Permeable pavement, pervious concrete, Sustainable material, Storm water, Environmental benefits, Cost.

Arivalagan.S /International Journal of ChemTech Research, 2018,11(06): 83-89. 


\section{Introduction}

Pervious pavement is designed to allow percolation or infiltration of stormwater through the surface into the soil below where the water is naturally filtered and pollutants are removed. In contrast normal pavement is an impervious surface that sheds rainfall and associated surface pollutants forcing the water to run off paved surfaces directly into nearby storm drains and then into streams and lakes. Permeable pavement is an alternative to traditional asphalt and concrete surfaces. Permeable pavement allows stormwater to infiltrate into either a storage basin below or exfiltrate to the soil and ultimately recharge the water table, while also potentially removing pollutants. Runoff from parking lots also carries pollutants, such as sediments, nutrients, and heavy metals, into surface waters. Permeable pavement is a potential solution; in lieu of $100 \%$ impermeable lots, perhaps a fraction of runoff can be reduced and pollutants be removed. Several best management practices were given credits for pollutant reduction, sediment reduction, and peak flow detention. Permeable pavement has not been included in BMPs receiving credit because they may clog. Recent studies have found positive results using permeable pavement with respect to both runoff reduction and water quality improvement. Permeable pavement has also been shown to act as a filter of such pollutants as lead and automotive oil .Figures 1 and 2, below, show examples of permeable interlocking concrete pavers and concrete grid pavers. Permeable interlocking concrete pavers are concrete block pavers that create voids on the corners of the pavers.

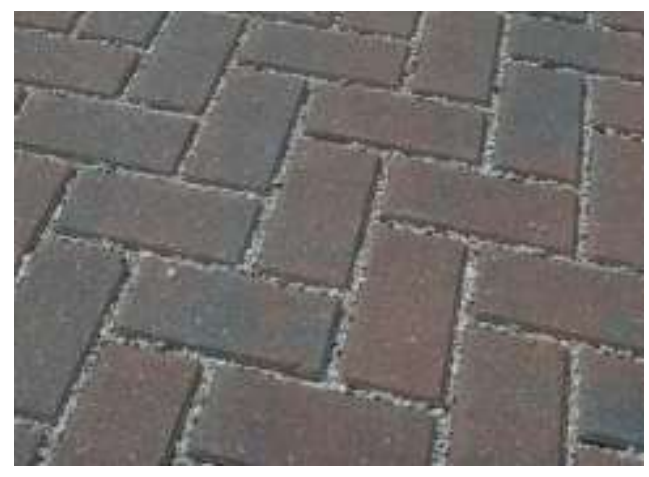

Figure 1: permeable interlocking concrete pavers

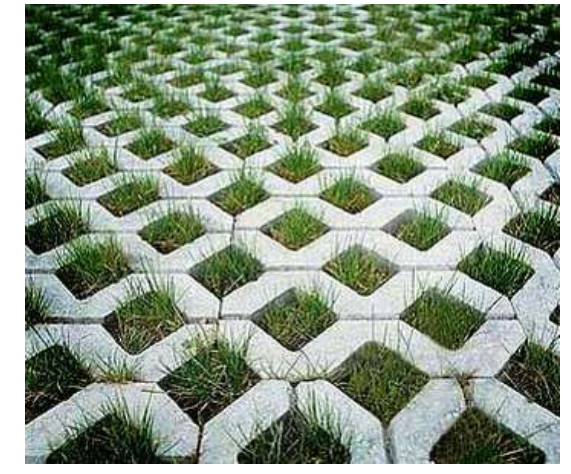

Figure 2: concrete grid pavers

\section{Literature Review}

Admute et al,(2017) in their study permeable pavements, highlight current trends in research and industry, and to recommend future areas of research and development. Permeable paving is a range of sustainable materials and techniques for permeable pavements with a base and sub base that allow the movement of storm water through the surface.

Agilandeswari et al.,(2017) Pervious concrete differs from the conventional concrete since it usually contains no or smaller amount of fine aggregate. When pervious concrete is used for paving, the open cell structures allow storm water to filter through the pavement and into the underlying soils. This pavement technology creates more efficient land use by eliminating the need for retention ponds, swell, and other costly storm water management devices.

Eva Arifi et al,(2017) performance of porous concrete made of recycled coarse aggregate was investigated. Fly ash was used as cement partial replacement. The strength of recycled aggregate was coMPared to low quality natural coarse aggregate which has high water absorption. Using fly ash up to $25 \%$ as cement replacement improves compressive strength and splitting tensile strength of porous concrete.

JianLianga et al.,(2017) we tested the effects of different admixtures at different dosages on compressive strength and water permeability of recycled pervious concrete. Through the research status-quo analysis of recycled pervious concrete, results show that all of the three admixtures can simultaneously increase the compressive strength to a certain extent and decrease the permeability coefficient. Their research findings provide an alternative of admixtures and their dosage in promoting the practical utilization of recycled pervious concrete. 
Ravi Teja et al.,(2017) were covered with impermeable surfaces like cement concrete and bitumen it leads to major impact on the ground water table. Pervious Concrete pavement is an effective way to minimize this issue. Pervious concrete is an opengraded structure with interconnected voids through which rain and storm water is permitted. Porous concrete is a new concept to increase theground water table level. The main aim of this work is to study the compressive strength of porous concrete by replacing the cement by fly ash.

Mohammed Sonebia et al.,(2016)climatic changes are occurring due to various human and industrial activities. porous concrete can help minimizing flooding risks, recharging ground water, reducing run off and peak flows, alleviating the precipitation load on overstressed drainage systems and improving water quality by capturing pollutants.

Deepika et al.,(2015) found aggregate in concrete is a structural filler which accounts for non-porous and impervious behaviour whereas pervious concrete is unique which uses a single size aggregate without fines and it would prove to be effective for growing environmental demands. Results of various mixes were compared and best mix was proposed based on infiltration and strength.

Than Mar Swea et al.,(2015)Pervious concrete is a special type of concrete with high porosity. The use of pervious concrete may achieve many potential LEED green building rating system credits. The objective of their research paper is to investigate the appropriate mix proportion which provides the high LEED points and also the good mechanical properties.

Tun Chi Fu et al.,(2014) altering parameters such as aggregate sizes, binder materials, and the amounts of binder used and were subsequently tested by using permeability, porosity, mechanical strength, and soundness tests. The results indicated that the water permeability coefficient and connected porosity decreased as the amount of binder used increased and increased with increasing aggregate size.

Uma Maguesvari et al.,(2013) presents the influence of fine aggregate and coarse aggregate quantities on the properties of pervious concrete. Fine aggregate was replaced with coarse aggregate in the range of 50 $100 \%$ by weight. Various mechanical properties of the mixes were evaluated. Coefficient of permeability was determined by using falling head permeability method. The relationship between the strength, abrasion resistance, permeability and total void present in aggregate based on angularity number has been developed. Suitability of pervious concrete as a pavement material is discussed.

\section{Pervious Concrete}

Pervious concrete pavement is a unique and effective means to address important environmental issues and support green, sustainable growth. By capturing stormwater and allowing it to seep into the ground, porous concrete is instrumental in recharging groundwater, reducing stormwater runoff, and meeting Environmental Protection..

In fact, the use of pervious concrete is among the Best Management Practices.recommended by geotechnical engineers for the management of stormwater runoff on a regional and local basis. This pavement technology creates more efficient land use by eliminating the need for retention ponds, swales, and other stormwater management devices. In doing so, pervious concrete has the ability to lower overall project costs on a cost basis.

Pervious concrete is a mixture of Portland cement, coarse aggregate or gravel, and water. Unlike conventional concrete, Typically, between $15 \%$ and $25 \%$ voids are achieved. This empty space allows water to infiltrate the underlying soil instead of either pooling on the surface or being discharged as runoff. Sidewalks and parking lots are ideal applications for pervious concrete. This is achieved by eliminating the finer particles such as sand from the concrete mixture Both the low mortar content and high porosity also reduce strength compared to conventional concrete mixtures, but sufficient strength for many applications is readily achieved. While the structural strength of porous concrete can be increased by adding larger amounts of cement, the porosity will decrease, thus decreasing infiltration rates.

Through this movement, pervious concrete mimics the natural process that occurs on the ground's surface, consequently reducing runoff and returning water to underground aquifers. It also traps suspended 
solids and pollutants, keeping them from polluting the water stream. Pervious concrete has many applications, most commonly:

low-volume pavements

residential roads and driveways

sidewalks

parking lots

low-water bridges

patios

well linings

walls (including load-bearing walls)

swimming pool decks

\section{Types of Porous Pavement}

There are three basic types of porous pavement, which are generally suitable as an alternative to the traditional impermeable surface:

Porous asphalt

Pervious concrete

Permeable interlocking concrete pavers

Both porous asphalt and pervious concrete are modified versions of the standard material where void space is created within the material to allow water to percolate through the pavement. This void space is created by removing a large portion of the fine aggregate in the mix design. Permeable interlocking concrete pavers, while not porous themselves, contain joints filled with small uniformly graded aggregate which allows for the passage of water.

Other porous surfaces such as grass and gravel pavers are also available depending on the usage of the surface and vehicle loading. These systems consist of rigid grids which are then filled with gravel or turf grass.

\section{Benefits of Pervious Concrete}

\section{Environmental Benefits}

Eliminates runoff

Recharges groundwater

Traps suspended solids and pollutants

Reduces surface temperatures and, therefore, the heat island effect

Eliminates the need for retention basins and water collection areas

\section{Financial Benefits}

Eliminates costs for retention basins, curbs, gutters, and other water collection installations

In winter conditions, typically requires much less salt or other de-icing products than traditional pavement types Lower installation costs (no underground piping, storm drains, or sloping/grading needed)

Low life-cycle costs with an equal life expectancy to that of regular concrete: 20 to 40 years when correctly installed

\section{Factors to Keep in Mind}

Runoff Volumes: A pervious pavement project should be properly designed to accommodate the amount of storm water runoff that is expected in the area. If not adequately designed, the water table below the pavement can rise, preventing storm water from being absorbed into the ground.

Because pervious concrete has such a high void content and its overall strength is generally lower than that of regular concrete, it is not recommended for highways, high-volume streets, potential spill sites (in case of clogging), and heavy loading areas. 
While it is estimated that porous concrete can be two to three times more expensive than regular asphalt or concrete, cost savings are simultaneously achieved as stormwater installations are not necessary.

Certain types of pervious pavements require frequent maintenance due to the possibility that solids and particles may get trapped and clog pavement pores. If the proper "vacuuming" or flushing is not carried out, pervious concrete will assume the traits of impervious concrete.

Sitting should be a major factor when considering permeable pavements. If the ground surface exceeds a $20 \%$ slope, storm water will run downhill over the permeable pavement as opposed to being absorbed by it as intended.

\section{Procedure For Calculating Infiltration Measurements}

Infiltration Measurements sites were tested in this study to determine infiltration rates. Double- or single-ring infiltrometers were used at each site to measure surface infiltration rates. Two sets of tests were run at 14 of the 16 Concrete Grid Paver sites, one set to measure existing conditions, and one set to measure "maintained" conditions. Each set of tests included three infiltration tests to help counteract variability in the surface conditions and infiltration rates. Locations for these tests were representative of the entire surface. This study used ASTM D 3385, is the Standard Test Method for Infiltration Rate in Field Soils Using Double-Ring Infiltrometer, as a basis to measure infiltration rates. This test is neither as accurate nor as precise as the doublering-infiltrometer test. However, this was a means of obtaining a rough of the surface infiltration rate.

\section{Quality of Water}

\section{Pollutant}

Permeable pavements are good in removing suspended solids and nitrogen. When an under drain system is provided into the pavement system, storm water is infiltrated and collected into the under drain, where nitrogen can be removed by plant uptake or denitrified. Along with atmospheric pollutants, harmful pollutant can also be emitting from road surfaces and roof material. Copper, hydrocarbons and lead show the highest pollutant concentration. Metal roof if not cleaned prior to discharge, usually show high concentrations of heavy metal in the corresponding runoff.

\section{Metals}

Studies have shown that the water quality is improving by filtration through permeable pavement systems, which work well in removing heavy metals and suspended solids from runoff. In comparison to pavements made of asphalt, concentration of copper, lead and zinc were significantly lower on permeable pavements. Generally permeable pavements are effective in trapping heavy metals in surface runoff. However, not all pavers have ability to trap dissolved heavy metals. The joint filling material for pavements with large joints should be such that it should not allow metals to pass through it. If so it may enter in groundwater resources.

\section{Hydrocarbons}

Diesel and oil fuel residue is frequently detected on non-permeable surfaces. In comparison, these were not detected on permeable pavements. If hydrocarbons are not removed in sufficient quantity during infiltration through surface layer it may endanger soil and groundwater. Many pollutants such as polycyclic aromatic hydrocarbon, phosphorous, metals and organic compounds are absorbed onto suspended solids. Models have been designed to estimate the suspended solids load during rainfall events, leading to better understanding of receiving waters being polluted by hydrocarbons. However, where certain detergents are present in the pavement system, they may contaminate the water, which may be require secondary treatment to improve its water quality.

\section{Cost Comparison}

The material cost for pervious concrete or porous asphalt is approximately $20 \%$ more than its conventional counterpart. This only considers surface material and does not account for the aggregate base material or other materials that may be used. Permeable Interlocking Concrete Pavers have a similar cost to 
traditional pavers although the cost of the aggregate used for the bedding layer and to fill the joints will be greater than the cost of sand used in impermeable pavers. While the material itself may be more expensive, the overall cost of the project is typically offset by the decreased need for traditional stormwater infrastructure and reduction of irrigation demands in nearby landscaped areas. Maintenance costs vary on a case-by-case basis, but porous pavement maintenance costs are generally comparable or less than traditional pavement.

\section{Maintenance Needs}

Porous pavement should be inspected and vacuumed or washed at least twice a year as preventative maintenance. Routine preventative maintenance will be more effective than corrective maintenance and ensure optimal performance of the system. It is essential to prevent opportunities for sediment to make its way onto porous pavement as this can clog the surface. If used in an area receiving snowfall or ice, it is important to avoid the use of sand and sand/salt mixes, which can cause clogging. It should also be noted that larger quantities of de-icers might be needed on porous pavement, as the materials will drain through the pavement rather than staying at the surface. Care should also be used when ploughing porous surfaces

\section{Other Considerations}

Porous pavement offers structural, economic, water quality, and storage benefits. In order to ensure a functioning porous system, it is necessary to have accurate design, proper construction/installation, and the development and implementation of maintenance plans. It is recommended that signs be installed where porous pavement is used to raise awareness and reduce the potential for improper maintenance. When considering the use of porous pavements, it is recommended that you seek contractors experienced with the product, preferably those with industry certification.

\section{Maintenance Practice Methods}

Regular maintenance actions for permeable pavements are recommended by all industries to decrease surface clogging and thereby ensure continuous surface infiltration. However, there is no standard maintenance or cleaning methods currently available.

Typical cleaning methods used include pressure washing and vacuuming. Mechanical sweeping is generally not recommended because the particles will be crushed and pushed farther into the pavement.

No specific frequency of cleaning is suggested, although at least once per year is recommended. A higher cleaning frequency may be needed depending on site and weather conditions. In addition, to avoid potential clogging, the application of sand is typically not recommended.

\section{Feature Study}

Up to now, the application of permeable pavement has been limited to some particular applications such as parking lots, low volume roads. Future research may allow for new and innovative applications such as village roads, airport runways. Permeable pavements generally have low strength but by increasing its strength and improving the properties it can be used for construction heavy traffic roads like Urban roads, Highway Shoulders, etc. Generally in densely populated area less land space exists. So that roads are not properly arranged and also surface drainage facilities are not provided properly. So in rainy seasons the problems of water clogging arises. So For these areas permeable pavement can become a good option. In parks or gardens jogging tracks or walkways are mainly constructed of compacted soils. But in rainy seasons these roads becomes muddy which cannot be used for their intended purpose. This causes various problems to pedestrians. So for this type of situations permeable pavements can be proven advantageous. Future research on effects of contaminants that remain in permeable pavement system should be taken under consideration. Also the impact of this system on environment after long time are unclear. Before all of this research has to be done to improve the lifespan of system as well as to reduce the cost of permeable pavement. If these problems were solved this system can be installed in more places in our country. 


\section{Conclusion}

This research study explains about the permeable pavements, its types, necessity and its present applications. This article also looked at various literature and studies conducted on permeable pavement systems. The quality of water and life span aspects were summerized for permeable pavement systems. Future research and scope of this system is discussed in this paper. The permeable pavement systems are changing the way of human development with natural environment. Its applications towards highways, road shoulders, parking lots and airport runways in India are all improvements in terms of water quality and safety.

\section{References}

1. Admute, Gandhi , Adsul, Agarkar, Bhor and Kolte, 2017, "Permeable Pavements: New Technique For Construction Of Road Pavements in India", International Research Journal of Engineering and Technology,Volume: 04, Issue: 04,pp.1801-1814.

2. Agilandeswari ,HajaAshif, Mohamed Sharafath ,Vadivel and Renukadevy,2017, “An Experimental Study on Performance of Pervious Concrete Using Partial Replacement of Recycled Concrete Aggregate" Vol. 6, Issue 5,pp.9175-9181.

3. Eva Arifi, EviNurCahya, and ChristinRemayanti N,2017, "Effect of fly ash on the strength of porous concrete using recycled coarse aggregate to replace low-quality natural coarse aggregate", American Institute of Physics, AIP Conference Proceedings , pp. 020055-1-020055-8.

4. JianLianga ,Xikai Dub , PuyuanLiua and Jianrui Shia,2017, "The Effect of Different Admixtures on the Basic Properties of Recycled Pervious Concrete",CHEMICAL ENGINEERING TRANSACTIONS, VOL. 59,pp.355-360.

5. Ravi Teja and SaiRanga Rao,2017, "PARTIAL REPLACEMENT OF CEMENT BY FLYASH IN POROUS CONCRETE”,International Journal of Civil Engineering and Technology, Volume 8, Issue 4, pp. 1099-1103.

6. Mohammed Sonebia, Mohamed Bassuonib and AmmarYahiac, 2016, "Pervious Concrete: Mix Design, Properties and Applications", RILEM Technical Letters, 1: 109 - 115.

7. Deepika, Lalithanjali,Ponmalar ,Vinushitha and Manju,2015,"'Influence of Recycled Aggregate based Pervious Concrete with Flyash", International Journal of ChemTech Research, Vol.7, No.6, pp 26482653.

8. Than Mar Swea ,PitchaJongvivatsakulb, and WithitPansukc, 2015,"Properties of Pervious Concrete Aiming for LEED Green Building Rating System Credits", ENGINEERING JOURNAL Volume 20 Issue 2,pp.61-72.

9. Tun Chi Fu, WeichungYeih, Jiang Jhy Chang, and Ran Huang, 2014,“The Influence of Aggregate Size and Binder Material on the Properties of Pervious Concrete" Advances in Materials Science and Engineering, Volume 2014 , Article ID 963971.

10. Uma Maguesvariand Narasimha , 2013, "Studies on Characterization of Pervious Concrete for Pavement Applications" ,2nd Conference of Transportation Research Group of India (2nd CTRG), Procedia - Social and Behavioral Sciences 104 ( 2013 ) 198 - 207. 